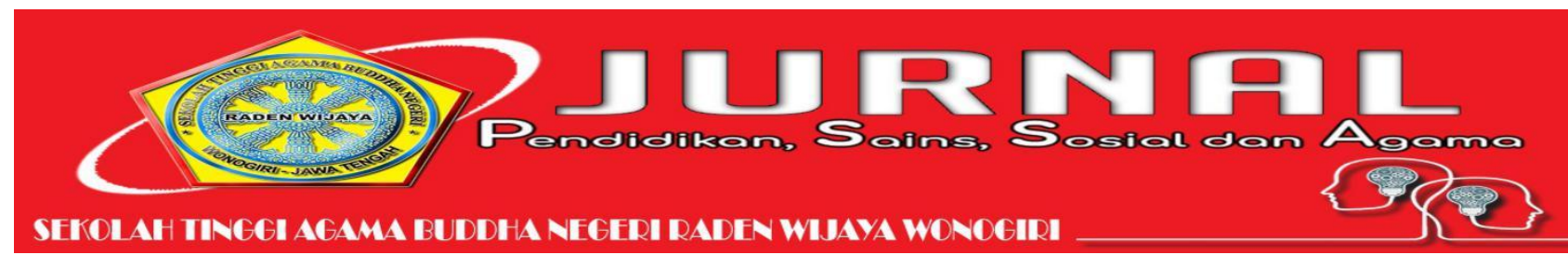

\title{
PENERAPAN PEMBELAJARAN PRAKTIK "TATA UPACARA KEAGAMAAN BUDDHA MAHAYANA" MELALUI DARING DENGAN ANALISIS PRETEST DAN POSTTEST DI STABN RADEN WIJAYA
}

\author{
Eko Siswoyo \\ STABN Raden Wijaya Wonogiri \\ ekomurni89@gmail.com
}

\begin{abstract}
Abstrak
Berawal dari kesulitan dalam pembelajaran daring tentang praktik dalam melaksanakan pembelajaran tata upacara keagamaan buddha disebabkan karena media yang kurang mendukung serta pengetahuan mahasiswa terhadap tata cara ibadah menurut tradisi Mahayana yang kurang diketahui oleh mahasiswa. Jenis penelitian ini dengan menggunakan analisis diskriptif kuantitatif yang berisi kata-kata dan Tindakan serta didukung dengan gambar. Pembelajaran ini telah dilaksanakan pada mahasiswa STABN Raden Wijaya Prodi Kepenyuluhan Buddha Semester III Tahun akademik 2021/2022 sebanyak 14 mahasiswa. Hasil penelitian dari pelaksanaan pembelajaran praktik dengan daring bahwa mahasiswa mampu praktik sesuai dengan harapan dan terjadi peningkatan yang ditunjukkan dengan hasil pretest dan posttest
\end{abstract}

Kata kunci: Daring Tata Upacara Keagamaan Buddha

\begin{abstract}
Starting from the difficulties in online learning about the practice of carrying out Buddhist religious ceremonial learning due to the media that is less supportive and students' knowledge of worship procedures according to the Mahayana tradition which is less known by students. This type of research uses quantitative descriptive analysis that contains words and actions and is supported by pictures. This learning has been carried out on students of STABN Raden Wijaya Buddhist Counseling Study Program Semester III Academic Year 2021/2022 as many as 14 students. The results of the research from the implementation of online practical learning that students are able to practice according to expectations and an increase is shown by the results of the pretest and posttest
\end{abstract}

Keywords: Online Buddhist Cerem 


\section{PENDAHULUAN}

Pendidikan adalah bagian tidak terpisahkan dari kebudayaan. Pendidikan yang berkebudayaan adalah pendidikan yang berorientasi pada pengenalan realitas diri dan manusia dalam relasi yang kompleks dengan realitas sosialnya. Pendidikan masa kini adalah pendidikan yang berupaya mendekatkan peserta didik dengan realitas kehidupan di sekitarnya. Pendidikan adalah aset yang sangat diperlukan untuk mencapai cita-cita perdamaian, kebebasan, dan keadilan sosial. Unesco mencanangkan landasan pendidikan global yang bertumpu pada empat pilar, yaitu: learning to know, learning to do, learning to be and learning to live together. Dalam konteks pendidikan tinggi empat pilar tersebut diimplementasikan melalui Tri Dharma Perguruan Tinggi yang bertujuan memberikan ruang bagi mahasiswa untuk secara aktif berkembang, spiritual keagamaan, pengendalian diri, kepribadian, kecerdasan, akhlak mulia, kreatif, mandiri, bertanggung jawab, dan berkarakter. Serta ketrampilan yang diperlukan dirinya, masyarakat bangsa dan Negara.

STABN Raden Wijaya sebagai perguruan tinggi keagamaan berupaya mewujudkan visi yang maju dalam ilmu pengetahuan, spiritual dan budaya pada tahun 2025. Sebagai upaya mewujudkan visi tersebut, STABN Raden Wijaya mempunyai misi untuk menyelenggerakan pendidikan, penelitian, Pengabdian kepada masyarakat serta menyelenggarakan tata kelola perguruan tinggi yang bersih dan akuntabel serta bebas dari korupsi SK nomor 15 tahun 2021

Dalam upaya mencapai visi tersebut, Sekolah Tinggi Agama Buddha Negeri (STABN) Raden Wijaya telah menyusun empat misi yang mendukungnya, yaitu: 1) Menyelenggarakan pendidikan dalam bidang kependidikan serta bidang nonkependidikan untuk menghasilkan manusia unggul yang mengutamakan ketaqwaan, kemandirian, dan kecendikian. 2) Menyelenggarakan kegiatan penelitian, dan menyebarluaskan ilmu pengetahuan, seni dan/atau budaya, yang berguna bagi masyarakat. 3) Menyelenggarakan kegiatan pengabdian dan pemberdayaan masyarakat yang mendorong pengembangan potensi masyarakat. 4)
Menyelenggarakan tata kelola yang baik, bersih, dan akuntabel

Maju dalam ilmu pengetahuan ditunjukkan melalui proses pendidikan, pengajaran, pembinaan dan pengembangan mahasiswa. Hal ini dilakukan sejak mahasiswa duduk pada semester awal, yang ditujukan untuk meningkatkan softskill lulusan dan pemberdayaan mahasiswa di bidang pengabdian kepada masyarakat. Peningkatan softskill lulusan diselenggarakan dalam rangka memberikan bekal kepada mahasiswa untuk menciptakan kualitas lulusan dapat berperilaku dan bersikap (afektif) sesuai profesi yang benar-benar dibutuhkan oleh para pemangku kepentingan (stackeholders). Melalui program ini, mahasiswa akan mendapatkan pengalaman langsung tentang cara berperilaku dan bertanggung jawab pada dunia kerja secara nyata (berlatih bertanggung jawab, berkomunikasi, dan beretika). Program peningkatan softskill lulusan mencakup berbagai kegiatan yaitu: pelatihan kewirausahaan, Pembinaan Mental Mahasiswa, Leadership, Microteaching, public relationship, peningkatan kemampuan teknologi informasi dan komunikasi, dan peningkatan melaksanakan Upacara Keagamaan Buddha. Krishnanda Wijaya Mukti 2020;95 dalam agama Buddha upacara ritual sesungguhnya merupakan suatu metode Upaya Kausalya dan tidak hanya merupakan puja bhakti, penghormatan dan persembahan, tetapi sekaligus bertujuan untuk memberi kekuatan pada praktisi dan mendorong perbuatan bajik.

Secara umum, capaian kinerja kegiatan peningkatan kemampuan softskill mahasiswa telah mencapai target. Untuk mencapai target sebuah pendidikan tinggi yang menjadi ujung tombak keberhasilan pendidikan yang salah satunya adalah dosen. Dosen merupakan bagian penting dalam meningkatkan kualitas sumber daya manusia melalui pendidikan. Sesuai dengan UU Nomor 14 Tahun 2005 tentang Guru dan Dosen, Dosen adalah pendidik profesional dan ilmuwan dengan tugas utama mentransformasikan, mengembangkan, dan menyebarluaskan ilmu pengetahuan, teknologi dan seni melalui pendidikan, penelitian, dan pengabdian kepada masyarakat. Profesionalisme dosen harus terwujud dalam tridharma perguruan tinggi, yaitu melaksanakan pendidikan dan 
pengajaran, melaksanakan penelitian dan melaksanakan pengabdian kepada masyarakat. Dosen adalah salah satu faktor pembangun generasi muda yang terpelajar, membantu memberikan bimbingan agar dapat membuat banyak orang dapat memajukan bangsa lewat pendidikan tinggi. Jadi seorang dosen seharusnya tidak bersikap masa bodoh pada mahasiswanya karena menganggap mereka adalah seorang telah dewasa dan tidak perlu banyak bimbingan, karena faktanya adalah jika dosen malas maka mahasiswa juga kan menjadi malas. Seharusnya dosen dapat memacu kerajinan mahasiswa agar mereka lebih bersemangat dalam mencapai tujuan mereka dalam kesuksesan proses belajar dan pendewasaan dalam meempersiapkan masadepannya.

STAB Negeri Raden Wijaya berupaya dengan maksimal untuk bersaing dan disesuaikan dengan perkembangan ilmu pengetahuan dan teknologi. Wujud kemajuan yang telah dilaksanakan diantaranya dalam bidang pendidikan dan pengajaran, penelitian dan pengabdian kepada masyarakat. Maju dalam ilmu pengetahuan dalam bidang pendidikan dan pengajaran tercermin dalam proses pembelajaran di STAB Negeri Raden Wijaya mengedepankan isu-isu terkini yang didukung dengan teknologi informasi internet, sehingga pelaksanaan proses pendidikan dan pengajaran dapat lebih unggul dibanding dengan PTKB lain di Indonesia.

Pendidikan luring di Indonesia terkendala adanya pandemi covid-19, demi mencapai tujuan pendidikan Sekolah Tinggi Agama Buddha Negeri Raden Wijaya Wonogiri menerapkan pembelajaran berbasis daring, SE Kemendikbud Nomor 15 tahun 2020. Pembelajaran berbasis daring di Sekolah Tinggi Agama Buddha Negeri Raden Wijaya kurang optimal. Pembelajaran daring yaitu penyelenggaraan kelas pembelajaran dalam jaringan untuk menjangkau kelompok target yang massif dan luas, sehingga pembelajaran daring dapat diselenggarakan dimana saja serta diikuti secara gratis maupun berbayar (Bilfaqih \& Qomarudin, 2015).

Dalam pembelajaran ini tidak adanya tatap muka antara dosen dan mahasiswa sehingga untuk mengetahui dan pembentukan karakter kurang terlihat. Selain itu dalam pemberlakuan tata tertib didalam perkuliahan juga kurang optimal. Disisi lain pembelajaran berbasis daring, kurang maksimalnya mahasiswa dalam mengerjakan tugas dikarenakan kurangnya referensi buku-buku dikarenakan kurangnya ebook yang terdapat pada Perpustakaan Sekolah Tinggi Agama Buddha Negeri Raden Wijaya Wonogiri.

Selanjutnya pembelajaran yang berbasis Praktik kurang terlaksana dengan baik. hal tersebut disebabkan belum adanya pertemuan tatap muka secara luring. Terutama pada mata kuliah tata upacara keagamaan buddha yang dalam materinya mengandung Praktik cara Puja Bhakti agama Buddha. Untuk itu diperlukan sebuah media agar pelaksanaan pembelajaran daring secara Praktik dapat terlaksana dengan baikMenurut Korth et al. (2009) menyatakan Guru yang memiliki kesiapan dalam pembelajaran dalam kondisi apapun akan meningkatkan kualitas guru.

Melalui hasil pengamatan terdapat beberapa hal yang perlu menjadi perhatian dalam praktik pelaksanaan Tri Dharma Perguruan Tinggi di STABN Raden Wijaya baik dalam pendidikan dan pengajaran, penelitian dan pengabdian kepada masyarakat. Menurut Korth et al. (2009) menyatakan dosen yang memiliki kesiapan dalam pembelajaran dalam kondisi apapun akan meningkatkan kualitas dosen. Dalam hal ini penulis akan lebih focus pada penerapan Pembelajaran Praktik Tata Upacara Keagamaan Buddha Tradisi Mahayana melalui Daring Berbasis pretest dan Posttest. Agar pembelajaran daring dapat berjalan dengan efektif, diperlukakan persiapan oleh pihak sekolah dan orangtua wali murid. Pihak sekolah memberikan fasilitas kepada guru berupa perangkat laptop atau hanphone kepada Dosen dan paket internet yang diperlukan.

\section{METODE}

Pendekatan yang digunakan adalah kuatitatif dengan desain penerapan pembelajaran praktek berbasis google classroom. Lexy. J. Moleong (2000: 112) Penelitian Kualitatif, mengemukakan bahwa sumber data utama dalam penelitian kualitatif adalah kata-kata dan tindakan, selebihnya berupa data tambahan seperti dokumen dan lainlain. Berkaitan dengan hal itu pada bagian ini jelas datanya dibagi ke dalam kata-kata dan tindakan, sumber data tertulis, foto dan statistic

Motode pegumpulan data menggunakan metode Pre test dan Posttest. Menurut Purwanto (2012:28) pretest yaitu tes yang diberikan sebelum pengajaran dimulai dan bertujuan untuk 
mengetahui sampai dimana penguasaan siswa terhadap bahan pengajaran (pengetahuan dan keterampilan) yang akan diajarkan. Setelah tes awal berakhir tenaga pengajar memberikan materi kepada peserta didik kemudian dilanjutkan dengan memberikan post test atau tes akhir. Pembelajaran praktik melalui daring. Model pembelajaran ini diujicobakan kepada mahasiswa semester III program studi Kepenyuluhan Buddha STABN Raden Wijaya Wonogiri tahun akademik 2021/2022 pada mata kuliah Tata Upacara Keagamaan Buddha yang berjumlah 14 orang.

\section{HASIL}

Berdasarkan pelaksanaan aktualisasi didapatkan data pre test dan post test yang diberikan kepada mahasiswa selain itu juga melaksanakan evaluasi terhadap pembelajaran (metode yang digunakan).

\section{Analisis Hasil Pretest}

Nilai terendah dari Pretest adalah 35 dan terendah adalah 80 dengan nilai rata-rata adalah 62. Hal ini dikarenakan mahasiswa belum mampu melaksanakan beberapa praktek dalam mata kuliah tata upacara keagamaan Buddha

Untuk mengetahi rentan dari hasil pretest maka dapat dikategorikan menjadi tiga yaitu rendah, sedang dan tinggi. Adapun rumus yang digunakan untuk mengetahui hasil pretest dan posttest sebagai berikut :

$$
\frac{N t-N r+1}{k}
$$

$\mathrm{Nr}$ : Nilai Tendah

$\mathrm{K}$ : Jumlah Kategori

\section{a. Hasil pretest}

Berdasarkan hasil prestest yang sudah dilaksanakan pada mahasiswa STABN Raden wiaya Wonogiri Prodi kepenyuluhan Buddha Semester III sebagai berikut :

$$
\frac{N t-N r+1}{k}=\frac{80-35+1}{3}=15
$$

Berdasarkkan rumus diatas didapatkan rentan nilai sebesar 15 point. Maka di buat tabel untuk menganalisa dan memahami pengukuran skor sebagai berikut :

\begin{tabular}{|l|l|l|c|}
\hline No & Rentan & Kategori & Jumlah \\
\hline 1 & $100-80$ & Tinggi & 1 \\
\hline 2 & $79-65$ & Sedang & 6 \\
\hline 3 & $\leq 64$ & Rendah & 4 \\
\hline
\end{tabular}

Dilihat dari analisis diatas maka dapat diketemukan bahwa yang mengikuti pretest presentasi nilai skor hasil sebagai berikut:

\begin{tabular}{|l|l|l|c|}
\hline No & Kategori & Jumlah & Prosentase \% \\
\hline 1 & Tinggi & 1 Mahasiswa & 7.14 \\
\hline 2 & Sedang & 6 Mahasiswa & 42,86 \\
\hline 3 & Rendah & 7 Mahasiswa & 50 \\
\hline
\end{tabular}

\section{Tahap pembelajaran}

Dalam tahap pembelajaran praktik tata upacara keagamaan Buddha media yang digunakan menggunakan aplikasi berbasis google classroom. Pembelajaran praktik tata upacara keagamaan Buddha terbagi menjadi tiga tahapan

Table 1.1

\begin{tabular}{|c|l|r|r|}
\hline No. & \multicolumn{1}{|c|}{ Nama } & \multicolumn{1}{c|}{ Pretest } & \multicolumn{1}{c|}{ Pottest } \\
\hline 1 & Rika Novi Susanti & $75 / 100$ & $90 / 100$ \\
\hline 2 & Lina suryaningsih & $55 / 100$ & $100 / 100$ \\
\hline 3 & $\begin{array}{l}\text { Nanda putra pratama } \\
\text { adhinata }\end{array}$ & $45 / 100$ & $85 / 100$ \\
\hline 4 & sri rohani & $75 / 100$ & $100 / 100$ \\
\hline 5 & Sumarmi & $50 / 100$ & $90 / 100$ \\
\hline 6 & Yuliyanti & $75 / 100$ & $85 / 100$ \\
\hline 7 & Endang Astari & $75 / 100$ & $75 / 100$ \\
\hline 8 & Winarti & $80 / 100$ & $100 / 100$ \\
\hline 9 & Mujiyanti & $75 / 100$ & $100 / 100$ \\
\hline 10 & Suyitno & $45 / 100$ & \\
\hline 11 & Hendrik & $50 / 100$ & $100 / 100$ \\
\hline 12 & Agung Susilo & $35 / 100$ & $100 / 100$ \\
\hline 13 & Andi & $55 / 100$ & $85 / 100$ \\
\hline 14 & Arisna dwi virya putra & $65 / 100$ & $90 / 100$ \\
\hline Pemaparan materi berupa PPT & & \\
\hline
\end{tabular}

a. Pemaparan materi berupa PPT dan Video Praktek

b. Pelaksanaan praktek yang sudah ditentukan

c. Evaluasi 


\section{Gambar 1.1 (Tahap I, Pemaparan Materi)}

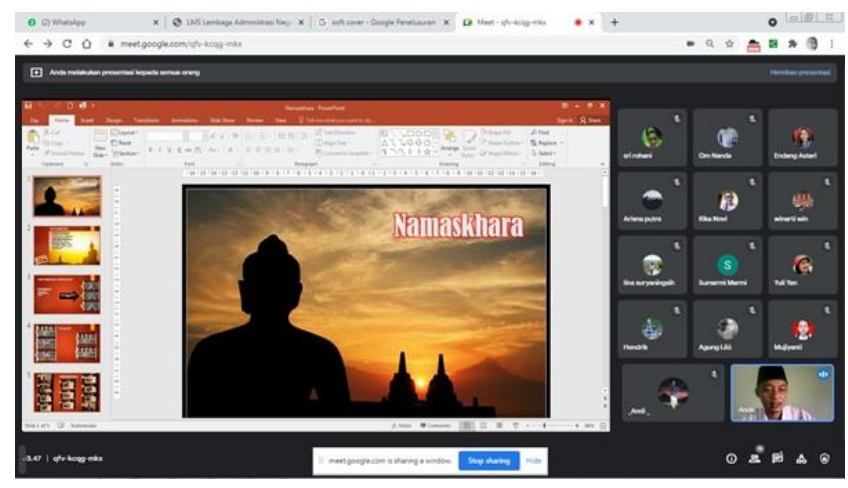

Gambar 1.2 (Tahap 2, Pembelajaran Praktek)

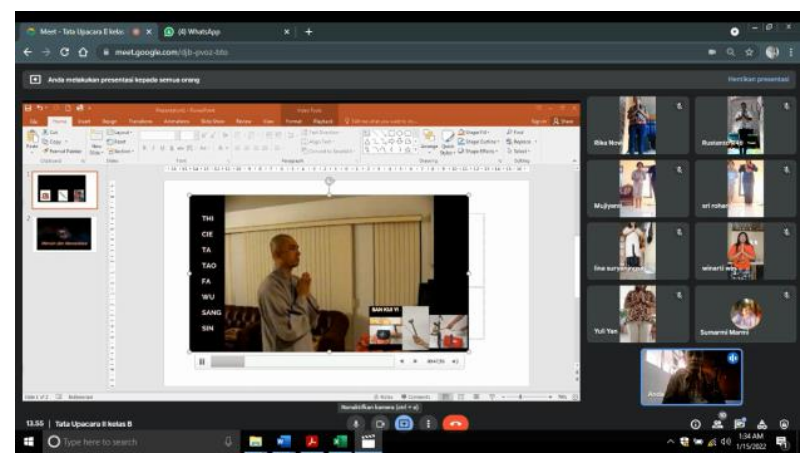

Pembelajaran bertujuan untuk mengetahui seberapa jauh keektipan pembelajaran praktek tata upacara keagaman Buddha melalui daring. Beberapa pembelajran Praktik yang dilaksanakan diantaranya:

a) Penerapan pembelajaran daring sincronus tentang Praktik Namaskara berbasis google meet

b) Penerapan pembelajaran daring sincronus tentang Praktik fa chi berbasis google meet

c) Penerapan Pembelajaran daring syncronus tentang Praktik Pembacaan Prajna Paramitha Hrdaya Sutra berbasis google meet

d) Pelaksanaan Pembelajaran daring Syncronus tentang memPraktikkan San Kui Yi berbasis google meet

\section{Hasil Posttest}

Berdasarkan pada Table 1.1 didapatkan hasil posttest Nilai Tertinggi dalam Post test ini adalah 100 sebanyak 6 mahasiswa, dan nilai terendah adalah 75 sebanyak 1 mahasiswa dengan rata-rata nilai 84. Hal ini terpengaruhi dengan adanya pelaksanaan aktualisasi kepada mahasiswa kepenyuluhan buddha dengan pembelajaran praktik tata upacara keagamaan buddha melalui daring.

Dalam menganalis hasil sama halnya dengan menghitung pada hasil prettest dengan memperhitungkan nilai rentan terlebih dahulu sebagai berikut:

$$
\frac{N t-N r+1}{k}=\frac{100-75+1}{3}=9
$$

Rentan nilai yang didapatkan dari hasil analisis adalah 8 point, maka berdasarkan hasil tersebut di buat tabel untuk menganalisa dan memahami pengukuran skor sebagai berikut :

\begin{tabular}{|l|l|l|c|}
\hline No & Rentan & Kategori & Jumlah \\
\hline 1 & $100-91$ & Tinggi & 6 \\
\hline 2 & $90-82$ & Sedang & 6 \\
\hline 3 & $\leq 81$ & Rendah & 2 \\
\hline
\end{tabular}

Berdasarkan dari analisis posttest diatas dan ada satu mahasiswa yang tidak mengisi posttest maka dapat diprosentasikan sebagai berikut:

\begin{tabular}{|l|l|c|c|}
\hline No & Kategori & Jumlah & Prosentase \% \\
\hline 1 & Tinggi & 6 & 42,86 \\
\hline 2 & Sedang & 6 & 42,86 \\
\hline 3 & Rendah & 2 & 14,29 \\
\hline
\end{tabular}

\section{KESIMPULAN}

Berdasarkan hasil evaluasi antara pretest dan posttest didapatkan bahwa melalui kegiatan ini terciptakan pemahaman tentang praktik tata upacara keagamaan Buddha Mahayana dengan menggunakan media daring. Hal ini dapat ditunjukkan dengan ilai perbandingan antara pretest dan posttest. Hasil postest menunjukkan nilai yang dikategorikan tinggi sebesar $42,86 \%$ sedangkan hasil pretest nilai yang dikategorikan tinggi sebesar 7,14\%.

\section{DAFTAR PUSTAKA}

Agus Sumantri dan Tim, 2020, Booklet Pembelajaran Daring. Direktorat pembelajaran dan Mahasiswa. Direktorat Jenderal Pendidikan Tinggi Kementerian Pendidikan dan Kebudayaan. 
Bilfaqih \& Qomarudin, 2015, Esensi Penyusunan Materi Pembelajaran Daring, Yogyakarta: Deepublish

Lexy. J. Moleong. 2000. Metodologi Penelitian Kualitatif. Bandung: PT Remaja

Krishnanda Wijaya Mukti, 2020, Wacana Buddha Dhamma, Jakarta: Yayasan Karaniya

Purwanto, Ngalim. 2012. Prinsip-Prinsip dan Teknik Evaluasi Pengajaran. Bandung: Remaja Rosdakarya

Risnajayanti, S.Pd, M.Pd1) , Silfiani2)

Pelaksanaan Pembelajaran Daring Pada Masa Pandemik, Jurnal Pendidikan Guru Pendidikan Anak Usia Dini; Universitas Muhammadiyah Kendari 